\title{
Festschrift edition of the Journal of Medical Ethics in honour of Raanan Gillon
}

\section{J Savulescu}

\section{Promoting respect for the four principles remains of great practical importance in ordinary medicine}

$\square$ his is a special edition of the journal to celebrate the contribution of Raanan Gillon to the field of medical ethics. The papers in this issue are from a festspiel in honour of Raanan held on the 17th of October 2003. The theme of the festspiel was method in medical ethics. Colleagues of Raanan were asked to outline their own approach to medical ethics, and how this differed from the four principles approach advocated by Raanan, as applied to four hypothetical cases which are also reproduced in this issue of the journal. ${ }^{1}$

It is a great privilege to be able to publish this series of papers, and Raanan's reply, in the journal for several reasons.

The first and most important of these is that they are a tribute to the enormous contribution Raanan has made to the field of medical ethics. Raanan has been a pioneer in medical ethics in the United Kingdom and beyond. He edited the Journal of Medical Ethics for over 20 years, retiring in 2001 . He has been instrumental in establishing medical ethics as a discipline, particularly within medical schools, in the United Kingdom. ${ }^{2}$ His book Philosophical Medical Ethics is one of the classics. ${ }^{3}$

While most people associate Raanan with his advocacy of the four principles, it is important to remember his approach is not restricted solely to application of the four principles. He is also one of the sharpest, wittiest, and most original thinkers in medical ethics. In a recent editorial, ${ }^{4}$-for example, Raanan disagreed with a judicial decision to impose separation of identical twins (against the wishes of their parents) which caused the death of one twin. He described it as "hubris". He argued that the grounds for the parents' decision (sanctity of life) was reasonable enough. He used this analogy. Identical twins are born. One has a condition which will kill it in a few months, but has a healthy heart and lungs. The other has a disorder of the heart and lungs. She will die soon without a heart lung transplant. With a transplant, she will survive. Unless the first twin is killed, both will die. If the first is killed and her heart and lungs taken, the second will survive. Raanan wrote that it would cause "outrage" to kill the one twin to save the other.

I learned a lot from this short editorial (although I do not agree with his argument..$^{5}$ ) The four principles were not prominent in this argument. It is a good old fashioned argument based on logical consistency, which Raanan has deployed so effectively since he first began as a philosopher/doctor. It is one of the basic paradigms of method in medical ethics. John Harris is particularly fond of this method, ${ }^{6}$ and presumably would describe it as unprincipled. ${ }^{7}$ Importantly, Raanan moves from this case to a principle about the legitimate scope of parental autonomy. This is a feature of casuistry which Tom Beauchamp argues is consistent with the spirit of the four principles approach. ${ }^{8}$

The second reason why this festschrift edition is so important is because the topic itself (chosen by Raanan)method in medical ethics-is so important. As Dan Callahan points out, there has been great change and development in field of bioethics. ${ }^{9}$ The range of ways of doing bioethics and medical ethics has vastly expanded, as have the numbers and backgrounds of people with an interest in medical ethics. It is important to know what medical ethics is and how one should do it, if one is to judge what is good and bad scholarship, what medical students should be taught, and which research is deserving of the increasing funds available for medical ethics research. Many doctors believe medical ethics is just about feelings, intuitions, or culturally specific values or that ethical dilemmas can be resolved purely through surveys of opinion or other empirical research. Raanan has fought very hard against this view of medical ethics.

The third reason this collection of papers is important is because they represent something significant about method in bioethics which is often lacking—collaboration. By collaboration, I do not only mean coauthorship. I mean a willingness to work constructively on other people's ideas and approaches. This has been the hallmark of Raanan's recent philosophical contributions. Many people in bioethics are obsessed with being the most original, the first, or the best, blindly demolishing all opposition. Raanan has taken the alternative, more reliable approach of building on what he sees as the strengths of the best existing philosophical approach to medical ethics in a constructive way. His work has been the paradigm of collaborative scholarship. The papers in the festspiel continue that tradition.

The final reason why this festschrift edition is important is because it illustrates another of the core elements of Raanan's work: a focus on the practical. Patti Gardiner ${ }^{10}$ and Alastair Campbell ${ }^{11}$ both stress the importance of real life detail in discussing medical ethics from a virtue ethics point of view. Indeed, Alastair laments a lack of detail in the cases proposed for discussion. Raanan's approach, however, has been practical and of great real life relevance in a different way. Raanan is rather rare in having been both a long-time practising doctor and a philosopher. His attraction to the four principles arises, I believe, from his acute insight into what would be of relevance and have the greatest impact on medical practitioners. It is clear that the four principles approach has been embraced by the medical profession and students.

Not only are the four principles accessible to professionals, they are also of great utility in improving medical practice, as the following example illustrates. Two years ago I broke my lower left leg, rupturing an artery to my leg and damaging the nerves to the foot. I had three operations and lost several litres of blood. After the last operation, my haemoglobin level was about five. The normal level is $14-18 \mathrm{~g} / \mathrm{dL}$. This is severe anaemia-death may occur around level three. Transfusion is normally performed when the haemoglobin falls below level eight.

Because my bleeding had ceased, the ruptured artery was repaired, and I was stable, I did not want a blood transfusion. I made a judgment that I did not want to incur the risks of transfusion. Although these are small, they are present. There are transmissible agents which cannot be tested for. There is also the possibility of error in testing or in giving blood. Since I was stable, my body would slowly replenish the lost blood at about $1 \mathrm{~g} / \mathrm{dL}$ per week.

The following morning, the chief surgeon visited me on a ward round surrounded by housemen and students. "Your haemoglobin should be 10," he said, walking off without bothering to 
inquire why I had refused a blood transfusion. (Transfusion guidelines had lowered the limit of transfusion some time ago from 10 to eight). I caught a glimpse of my medical notes. A nurse had written: "Refusing blood". In fact, I was not refusing blood-I was only refusing to have a blood transfusion while my condition was stable. If I had bled more, I would have wanted to have a transfusion to save my life. I had made this clear. But it had apparently not got through.

A number of doctors, some of them friends, tried to convince me to have blood. I asked to speak to the head of haematology, whom I knew. I asked what evidence there was that a transfusion at this stage (where I was no longer losing blood) would help me. She did not cite any. I asked if I could have human erythropoietin, a hormone which can stimulate one's own bone marrow to produce its own red blood cells. It is produced artificially so it does not have any infectious risks. She said it was not given in these acute situations. I said I thought Jehovah's Witnesses received it when they refused blood on religious grounds. She said there was no evidence it would have any beneficial effect in a situation of acute blood loss. I said that none the less, because it had no risks, I would like to have it. I would pay for it myself. She said she could not let me pay. So I could not have it. Some days later a rehabilitation representative visited me who was a Jehovah's Witness. He told me that Jehovah's Witnesses do receive erythropoietin in such situations.

My experience (as a very well informed patient who is also a doctor) was that it was very difficult for me to make my own decision about whether to receive blood. I then had to resist enormous pressure on me to take blood. There was no scope to accommodate my own secular values, though Jehovah's Witnesses were more likely to be accommodated because their values were based on religion instead of self interest. While several authors describe the example in this festschrift edition of the Jehovah's Witness refusing blood as a "standard case", and indeed "standard case" is part of the title of the scenario, my attempt to express my own values, to request information, and to make my own choice about blood seemed to totally throw the medical establishment. How could someone question a doctor's advice and medical orthodoxy to have a transfusion if the haemoglobin fell below eight? I had great difficulty in expressing and acting on my own autonomous values.

When Dan Callahan claims there is an excessive importance laid on respect for autonomy, I find myself siding with Raanan. Enormous medical paternalism still remains. Many doctors still lack any concept of what it is to respect a patient as a person. Promoting respect for autonomy in particular and the four principles in general, while perhaps not so novel in bioethics now, is still of great practical importance in ordinary medicine.

\section{Author's affiliation}

\section{REFERENCES}

1 Gillon R. Four scenarios. J Med Ethics 2003;29:267-8

2 Hope T. Raanan Gillon: editor for twenty years. J Med Ethics 2001;27:78-9.

3 Gillon R. Philosophical medical ethics. Chichester: Wiley, 1985.

4 Gillon R. Imposed separation of conjoined twins - moral hubris by the English courts. $J$ Med Ethics 2001;27:3-4.

5 Savulescu J. The embryonic stem cell lottery and the cannibalisation of human beings. Bioethics 2002;16:508-29.

6 Harris J. Stem cells, sex, and procreation. Camb Q Healthc Ethics. In press.

7 Harris J. In praise of unprincipled ethics. J Med Ethics 2003;29:303-6.

8 Beauchamp T. Methods and principles in biomedical ethics. J Med Ethics 2003;29:269-74.

9 Callahan D. Principlism and communitarianism. J Med Ethics 2003;29:287-91.

10 Gardiner P. A virtue ethics approach to moral dilemmas in medicine. J Med Ethics 2003:29:297-302.

11 Campbell A. The virtues (and vices) of the four principles. J Med Ethics 2003;29:292-6.

\section{$\mathrm{ECHO}$}

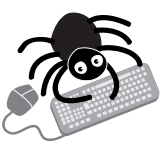

Please visit the Journal of Medical Ethics website [www. jmedethics.com] for link to this full article.

\section{Researchers have a new option for testing patients' role in clinical decisions}

The first accurate measure of patient participation in clinical decisions will ultimately help

to determine whether this involvement improves patient outcome, say its creators. An

evaluation study of its performance has already shown that general practitioners (GPs) actually share decisions with their patients much less than their positive attitude would suggest.

Mean score with the OPTION scale for patient involvement in decisions in consultations with 21 GPs on a scale of 0-100 was low (16.9 (SD 7.7) 95\% confidence interval 15.8 to 18.0; minimum score 3.3, maximum 44.2). Distribution of scores was skewed towards low values.

The scale performed well in tests of validity and reliability. Within constructs measures of rater agreement within each item, agreement among raters, and homogeneity of the scale all indicated the score's reliability. Construct validity was also demonstrated.

The scale was devised to satisfy accepted competencies for making shared decisions. It was piloted among GPs and non-clinical raters, using audiotaped simulated consultations covering a range of patient involvement, then refined in an iterative process. Its performance was judged with 186 taped routine consultations conducted by 21 GPs in the study; all were principals of one to 10 years in Gwent, South Wales, UK.

Patient autonomy and professional truthfulness are basic tenets of patient involvement in clinical decisions. There is intense interest from all sides about the potential to affect health outcome. However, outcome studies have not had the benefit of a bespoke measure of patient participation. The scale can be used for all consultations.

- Quality and Safety in Health Care 2003;12:93-99. 